\title{
Present crustal deformation pattern in the Pancardi Region: Constraints from Space Geodesy
}

\author{
G. Grenerczy ${ }^{1}$, I. Fejes ${ }^{1}$, and A. Kenyeres ${ }^{1}$ \\ ${ }^{1}$ Satellite Geodetic Observatory, FÖMI, P.O.Box 546, H-1373 Budapest, Hungary
}

Received: 2 May 2000 - Accepted: 27 March 2002

\begin{abstract}
It was almost a decade ago when the first space geodetic project was commenced in the PannonianCarpathian-Dinaric (PANCARDI) region with the aim of direct measurement of present crustal movements and strain. The most effective space geodetic technique for this purpose turned out to be the Global Positioning System (GPS). Several countries established their own national GPS network for monitoring crustal deformation. Nowadays stations of global, continental, regional, national and many local networks operate in the territory of the study area. An overview of these GPS geodynamic programs is given in the first section, then we analyse the data of the regional and the Hungarian national program and give short reports from other projects in the PANCARDI region. In our analysis we compare the velocities derived from space geodesy with those predicted by the NNR-NUVEL1A model based on geological and geophysical records. Looking into the intraplate crustal velocities the data show a fairly stable Bohemian Massive (BM) with relative crustal velocities smaller than $1 \mathrm{~mm} / \mathrm{yr}$. With reference to the BM in the north, the western part of the Alpine-North Pannonian (ANP) unit is moving to the East (E) with generally $1 \mathrm{~mm} / \mathrm{yr}$ velocity that increases to more than twice this value towards its westernmost parts. The largest principal strain rate between these tectonic domains is a NE-SW oriented contraction $\left(-8.6 \pm 2.5 \times 10^{-9} / \mathrm{yr}\right.$ $(\mathrm{ppb} / \mathrm{yr}))$ over an approximately $300 \times 300-\mathrm{km}$ area. Here we observe left-lateral shear rate $\left(97^{\circ} \pm 7^{\circ} ; 10 \pm 2 \mathrm{ppb} / \mathrm{yr}\right)$ between the Alpine-North Pannonian unit and the Bohemian Massif. South of the Alpine-North Pannonian unit the complex structure of junction of several tectonic domains can be described by northward trending velocities with $1-2 \mathrm{~mm} / \mathrm{yr}$ north component relative to the ANP unit or the BM. The direction of contraction near the boundary of the Adriatic microplate is NW-SE oriented with magnitude of $-8.0 \pm 5.3$ $\mathrm{ppb} / \mathrm{yr}$ over an area of $300 \times 120-\mathrm{km}$. Here we observe E$\mathrm{W}$ oriented $\left(93^{\circ} \pm 13^{\circ}\right)$ right-lateral shear $(12 \pm 5 \mathrm{ppb} / \mathrm{yr})$ be-
\end{abstract}

Correspondence to: G. Grenerczy (grenerczy@sgo.fomi.hu) tween the ANP unit and the southernmost sites in the Dinarides and Southern Alps. These imply that the northward moving Adriatic region is presently squeezes out the ANP unit to the East from between the BM and the Adriatic microplate. Except for a couple of sites the eastern section shows no significant velocities yet. It seems likely that the eastward escape is absorbed in the central section of the ANP in the Pannonian basin since no detectable eastward component found for the site velocities in the eastern, north-eastern part of the ANP unit.

\section{Introduction}

The Pannonian basin and its surrounding orogens are situated in the territory of twelve countries. Although most of them carry out national space geodetic research for investigations of present crustal deformation of the country, because of the small extent of these networks, none of them is large enough for understanding the present crustal deformation pattern of the Pannonian basin system. The first and only international co-operation on GPS geodynamic research covering the whole PANCARDI region is the Central Europe Regional Geodynamics Project (CERGOP). Since the Central European GPS Geodynamic Reference Network (CEGRN) is a regional reference network, its spatial resolution (site density) is inadequate to constrain the kinematics in fine detail. National and local investigations should complement the large-scale picture with their better resolution. We, therefore, believe that it is worthwhile to give a brief overview of each national project since their future integration could provide the best spatial resolution of space geodetic information about the present tectonics of the region. However, up to now only some of them presented their results that will be summarised below. Our primary focus will be on the regional project covering the whole study area however, complementary data from the Hungarian network will also be presented. 
Table 1. National GPS geodynamic networks in the PANCARDI region. OLG: Observatory Lustbuehel Graz, VUGT: Research Institute of Geodesy, Topography and Cartography, FOMI SGO: Institute of Geodesy and Remote Sensing Satellite Geodetic Observatory, WUT, Warsaw University of Technology, GCI: Slovakian Geodetic Survey, GIK: Geodatische Institute, Karlsruhe, MAO: Main Astronomical Observatory

\begin{tabular}{|c|c|c|c|c|c|c|c|}
\hline Network & Country & No. of sites & Epoch measurements & $\begin{array}{l}\text { Processed } \\
\text { in }\end{array}$ & $\begin{array}{l}\text { Current } \\
\text { status }\end{array}$ & $\begin{array}{l}\text { Responsible } \\
\text { institution }\end{array}$ & Reference \\
\hline AGREF & $\begin{array}{l}\text { Austria } \\
\text { Slovenia } \\
\text { Croatia }\end{array}$ & $\begin{array}{c}185 \\
\text { (partly } \\
\text { monitored) }\end{array}$ & 1990-92/93/94/95 & Graz & closed & OLG, Graz & Erker et al., 1997 \\
\hline GEODYN & Czech Rep. & 34 & $1995 / 96 / 99$ & Pecny & active & VUGT, Pecny & Simek, 1999 \\
\hline HGRN & Hungary & 13 & 1991/93/95/97/99 & Penc & active & FOMI SGO, Penc & Fejes et al., 1993 \\
\hline $\begin{array}{l}\text { Extended } \\
\text { SAGET }\end{array}$ & $\begin{array}{l}\text { Poland and } \\
\text { other C.E. } \\
\text { countries }\end{array}$ & $23-50$ & $\begin{array}{l}\text { 1992/93/94/95/ } \\
96 / 97 / 98 / 99\end{array}$ & Warsaw & active & WUT, Warsaw & Sledzinski, 1994 \\
\hline $\begin{array}{l}\text { SLOVGE- } \\
\text { RENET }\end{array}$ & Slovakia & 24 & $1993 / 95 / 99$ & Bratislava & active & GCI, Bratislava & Priam, 1995 \\
\hline CRODYN & Croatia & $22-28$ & $1994 / 96 / 98$ & Frankfurt & closed & $\begin{array}{l}\text { University of } \\
\text { Zagreb }\end{array}$ & Solaric, 1999 \\
\hline SEAGC & $\begin{array}{l}\text { Sout-East } \\
\text { Alpine region }\end{array}$ & 90 & 1995 & $\begin{array}{l}\text { Frankfurt, } \\
\text { Graz }\end{array}$ & closed & OLG, Graz & Marchesini, 1998 \\
\hline $\begin{array}{l}\text { Vrancea } \\
\text { network }\end{array}$ & $\begin{array}{l}\text { Romania } \\
\text { (local) }\end{array}$ & 26 & 1997 & Karlsruhe & active & GIK, Karlsruhe & Ghitau, 1998 \\
\hline GEODUC & $\begin{array}{l}\text { Ukraine } \\
\text { (local) }\end{array}$ & 12 & 1993/94 & Warsaw & closed & $\begin{array}{l}\text { MAO, Kiev, } \\
\text { Ukraine }\end{array}$ & Baran et al., 1994 \\
\hline
\end{tabular}

\section{Review of space geodetic projects investigating the present geodynamics of the Pancardi Region}

2.1 National GPS geodynamic projects and their current status

By the early nineties many Central European countries have established national GPS reference networks for crustal deformation studies. The site monumentation and the measurements carried out on them were of very high precision generally surpassing the requirements for the geodetic control networks. Each of these countries established their own data, processing, and analysis centres. Integration and crossborder co-operations started early and countries like Austria and the former West Germany provided extensive help in establishing GPS geodynamic networks on international level outside their territories (e.g. in Slovenia, in Croatia, in Romania, etc.). Based on the available literature, Table 1 gives a summary of epoch type GPS geodynamic networks in hands of national institutions in the region. A large number of sites of the national networks became integrated into higher level regional e.g. CEGRN, EUREF (European Reference Network) and the global IGS (International GPS Service) GPS network. Therefore, they may be considered as densification of the higher level networks as well. There are a large number of local GPS networks in the region for defor- mation studies, which are not listed here mainly because their limited geographic extension and scope of investigations.

2.2 CERGOP, the first international co-operation in GPS geodynamic research covering Central Europe

The Central Europe Regional Geodynamics Project is a longterm European project focusing on the GPS monitoring measurements of ongoing tectonic processes in Central Europe. CERGOP was initiated in 1993 by Hungarian and Polish scientists under the umbrella of the Central European Initiative (CEI) with the participation of 11 countries: Austria, Croatia, the Czech Republic, Germany, Hungary, Italy, Romania, Poland, Slovakia, Slovenia and Ukraine. As associated country Bulgaria joined the project in 1996. In the timeframe 1995-98 the project was supported by the European Commission. This was the first international co-operation in a broad sense of GPS geodynamic research in the Central European region. The first phase of the project was concluded successfully in 1998 (Fejes et al., 1998). The main objectives were the following:

- The integration of geodynamic research in the Central European region based on GPS measurements.

- Investigation of the most profound geotectonic features in the Central European region, the Teisseyre-Tornquist 
zone, the Carpathians, the Pannonian basin and their relation to the Alpine - Adria region.

- Establishment of a stable reference frame for subregional, across the borders or local investigations and deformation studies in the region.

The most important step in CERGOP activities was the establishment of the Central European GPS Geodynamic Reference Network in 1993-94. This network served as the main tool to achieve the project objectives and in fact materialised one of the most important products of CERGOP. CEGRN consists of 31 sites and lies approximately between $11^{\circ}$ $24^{\circ} \mathrm{E}$ Longitudes and $44^{\circ}-54^{\circ} \mathrm{N}$ Latitudes. This geographic area covers the Palaeozoic and Precambrian Platform of the Polish German Depression, the Bohemian Massive, the East Alpine Region, part of the Julian Alps, the Carpathians, the Pannonian Basin and part of the Eastern European Platform. The network design concept contained five main conditions, which were to be satisfied by all sites of CEGRN:

- The sites should be placed on all the main geological, structural elements of the region.

- The sites and monumentations should satisfy optimal conditions for GPS observations with geodynamic purposes.

- The rules of the global-regional-local hierarchy should be strictly followed e.g. include overlapping sites with local and global networks.

- Include collocated Satellite Laser Ranging (SLR) and Very Long Baseline Interferometry (VLBI) sites into the network.

- The number of sites should be limited to about 30.

From this design concept it was evident that the main role of CEGRN was to provide a stable reference frame in the area. Tectonically interesting or active areas should be studied by local densification of the network. In fact the participating countries have also developed national GPS geodynamic networks, which served as subnetworks or local densification to CEGRN in the GRL hierarchy. The CERGOP Data Centre was established in 1994 and was hosted by the Observatory Lustbuehel in Graz, Austria. All observational data related to CERGOP are stored and archived here. In the time interval 1994-98 four CEGRN monitoring campaigns were carried out. Strict rules for the GPS measurements were laid down and followed. Following the campaigns the data were sent electronically to the CERGOP Data Centre in Graz, Austria, where it was made available to all CERGOP processing groups. By 1998, 11 of the 31 CEGRN sites were operating permanent GPS stations.

The observational data were processed in the 8 CERGOP Processing Centres (Graz, Austria; Penc, Hungary; Warsaw, Poland; Bratislava, Slovakia; Frankfurt, Germany; Matera, Italy; Pecny, Czech Republic and Zagreb, Croatia). Most of the processing centres used the BERNESE software package.
The Italian group used the GIPSY and the MICROCOSM software packages. The work of the processing groups was co-ordinated and evaluated by a Study Group. The final results of the processing centres were the coordinate and covariance sets for each day of the CEGRN observational campaigns.

\subsection{CERGOP 2 - extension towards the South and East}

Encouraged by the highly interesting initial results of the first phase of CERGOP and the very efficient collaboration, the representatives of the 11 participating countries agreed to work out the concept of the next phase - CERGOP 2 - and continue the project in the following 3-5 years (Fejes 1999).

The main objectives of the second phase are the following:

- Extension and densification of the Central European Regional Geodynamic Network (CEGRN) in order to include new, tectonically relevant sites.

- Maintenance the Central European Terrestrial Reference Frame (CETRF).

- Provision a reliable 3 dimensional tectonic velocity field covering the Central European Region and integrate this into hierarchically higher level (i.e. global) tectonic models.

- Analyse kinematic results and give geophysical interpretations.

- Support local geodynamic research, environmental studies, seismic hazard assessments, GPSmeteorological studies etc. in the Central European Region based upon the high accuracy space geodetic measurements, carried out on an integrated geodynamic network, the CEGRN.

In addition to the earlier 11 participating countries, three new member countries have been accepted: Albania, Bosnia Herzegovina and Bulgaria. The number of CEGRN sites increased from 31 to 63 . The increased number of sites is partly due to the new members, but dominantly to additional sites in the earlier member countries. Figure 1 shows the Central European GPS Geodynamic Reference Network (CEGRN-2). The first CEGRN-2 GPS campaign on the extended network was organised between 14-19 June 1999. Future campaigns are anticipated in 2001 and in 2003.

\subsection{UNIHIP a new initiative for integration of national GPS geodynamic networks}

Unified National High Precision GPS Networks in Central Europe - UNIHIP is a planned co-operation among the operators of the precise national GPS geodynamic networks of Austria (AGREF) the Czech Republic (GEODYN), Germany, Hungary (HGRN), Poland (SAGET), Slovakia (SLOVGERENET). These national networks were developed independently in the early nineties and can be considered as part of the national research infrastructures in the field 


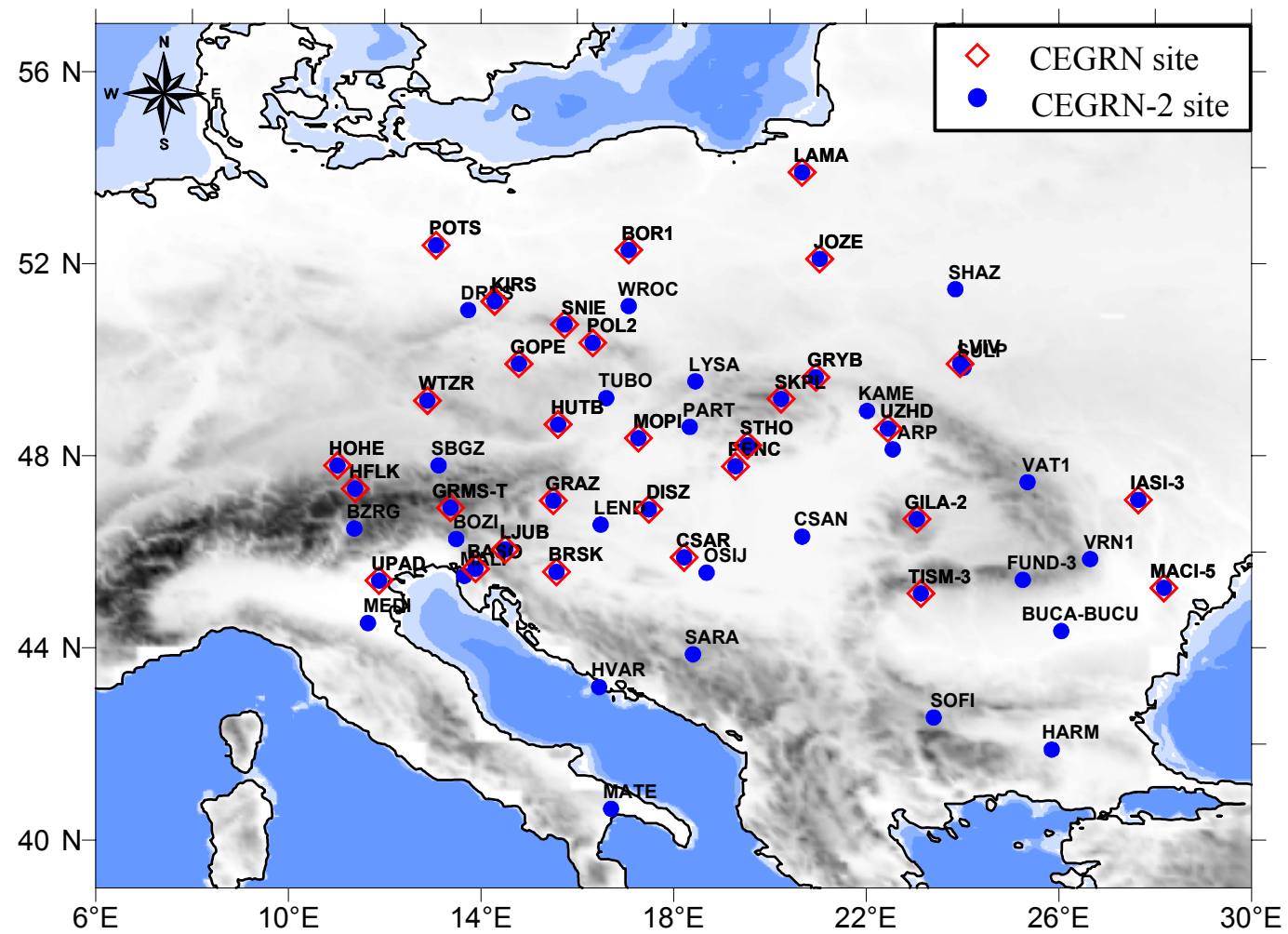

Fig. 1. GPS sites of the Central European GPS Geodynamic Reference Network (CEGRN). Blue dots represent the CEGRNII (the extended CEGRN) sites first measured in 1999. The red symbols show the original CEGRN sites measured during the first phase of the project as well from 1994 to 1997 and during the second phase in 1999.

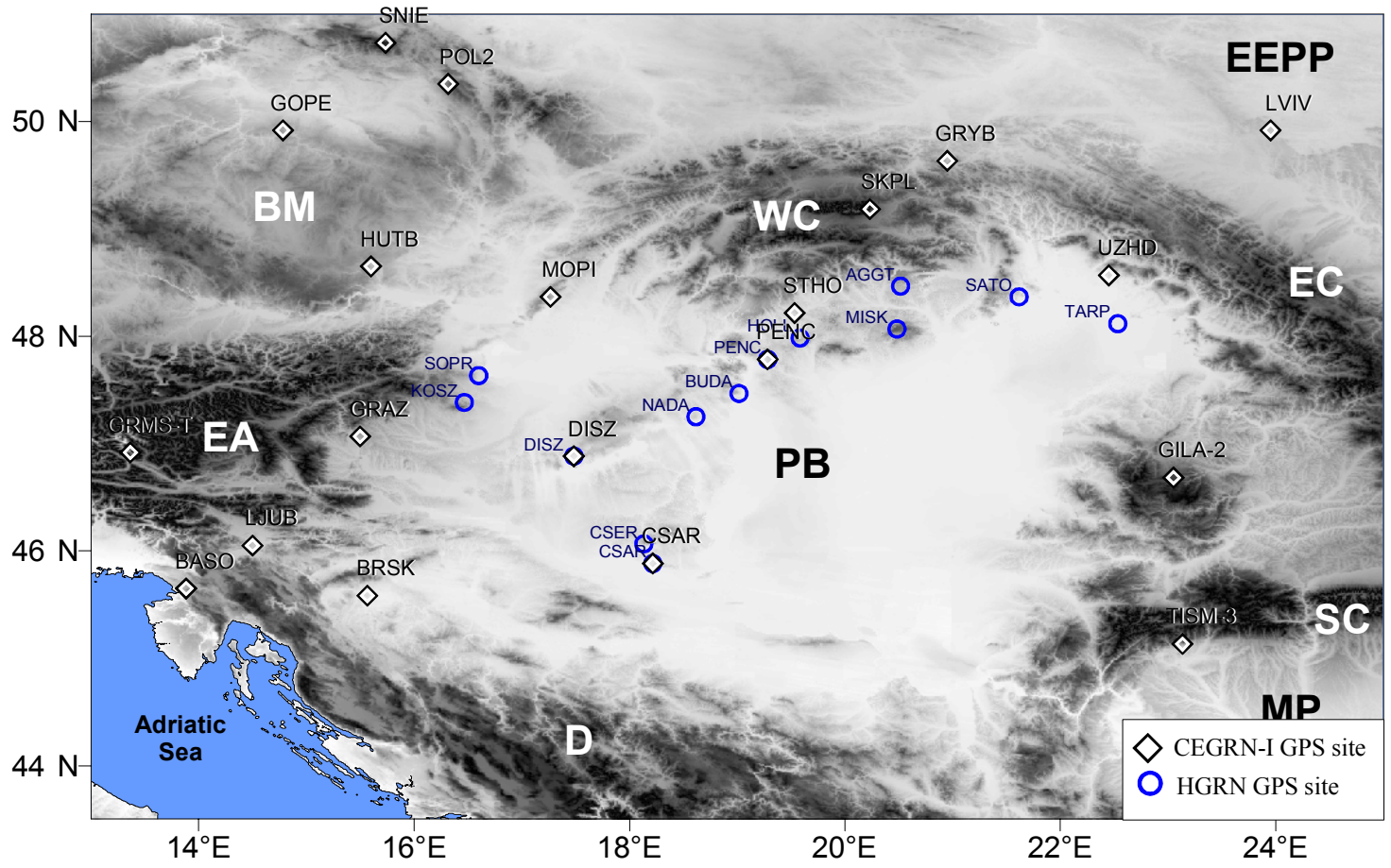

Fig. 2. Image of the Pannonian basin and the surrounding orogens showing their topographic features. PB is the Pannonian basin, BM is the Bohemian Massif, EEPP: East European Precambrian Platform, D: Dinarides, EA is the Eastern Alps, WC, EC and SC are the Western, Eastern and Southern Carpathians respectively. ๑ symbols show the HGRN sites, the $\diamond$ indicate those of the CEGRN. 


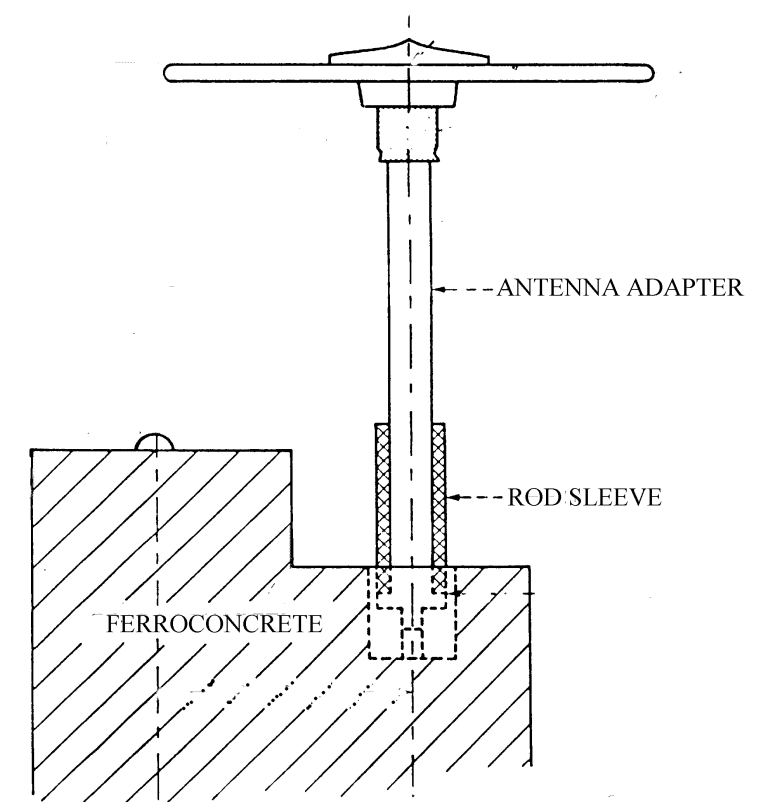

Fig. 3. Antenna adapter for high precision GPS deformation monitoring. The antenna mounting is forced-centred and provides antenna set up repeatability about $0.5 \mathrm{~mm}$. The adapter length is $305 \mathrm{~mm}$.

of geosciences, supporting geophysical research, tectonic plate boundary mapping, environmental protection, seismic risk assessments etc. Each of them has accumulated a considerable asset in the form of databases containing series GPS position measurements with extreme high precision. The values of these databases are continuously increasing with time because the longer time-base allows more accurate tectonic velocity determination and more accurate assessment of consequences even when the accuracy of the position measurement remains the same. Merging these databases and operating these networks co-ordinated, will increase the value of this infrastructure considerably and will open up a row of new applications on an international level. Coordination will involve synchronised GPS observations, unified database structure, standardisation of formats, processing techniques, quality assessment and quality assurance. The product will be a virtual, large-scale research infrastructure in Central Europe, which will attract students, and scientists from many disciplines like geophysics, geodesy, earthquake research, large-scale industrial development projects, etc.

\section{Building and operating the networks}

The Pannonian basin system belongs to the broad plate boundary zone between Eurasia and Africa. Although it is situated north of the actual boundary of the two plates it is still affected by the microplates between them. Monitoring tectonic motion is one of the most challenging activities of geodesy and geophysics. This statement is especially valid

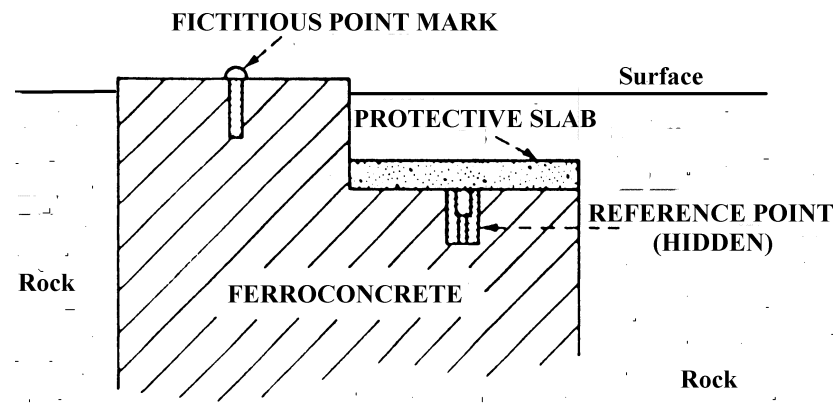

Fig. 4. Special GPS mark for crustal deformation studies designed by the Satellite Geodetic Observatory. These step type monumentations are used during the establishment of the HGRN network. Each step is $10 \mathrm{~cm}$ wide rectangle from top view.

for areas like the PANCARDI region (Fig. 2), where low rate intraplate displacements are expected. There are three cardinal points of modern, GPS based geodynamics: longterm stability monumentation, appropriate measurement cycles and careful data analysis. These facts have to be treated very carefully in order to extract the most reliable results. In the following these highlights are discussed based on the practice followed in the HGRN and CEGRN networks.

\subsection{GPS site selection and monumentation}

Detecting tectonic displacements is always a long-term activity. The GPS technique entered the stage only at the end of the eighties, but it has quite different technical background compared to the traditional techniques. Formerly the levelling was the only monitoring tool for detailed studies on national and regional scales but it was capable only to detect vertical displacements (Joó et al., 1990). The monumentation and distribution of the levelling benchmarks was inappropriate for the GPS, therefore in the majority of cases new sites and new networks had to be established. One side this transition made possible the re-definition and improvement of network structures, monumentation types but on the other side it was hardly possible to transfer the information content of the previous studies.

The establishment and further treatment of the HGRN network gives an excellent example for the modern GPS geodynamic networks. At the site selection the tectonic significance and the GPS requirements were taken into account. Particular care was devoted to the monumentation for satisfying the requirements of mechanical stability, long life expectancy and reliable antenna set up repeatability. All HGRN sites, except for PENC permanent station, were monumented into bedrock using a special observing monument and antenna adapter (Fig. 3) directly designed for GPS geodynamics (Fejes, 1991). This type of monumentation allows antenna set up repeatability within $0.5 \mathrm{~mm}$, minimises the multipath effect of the GPS signal and the camouflaged marker allows long life expectancy (Fig. 4). This monumentation was successfully applied also in Italy (volcano Etna), Slovakia (SLOVGERENET) and Ukraine (GEODUC). 
Table 2. The HGRN epoch campaigns

\begin{tabular}{llcccc}
\hline $\begin{array}{l}\text { Campaign } \\
\text { name }\end{array}$ & $\begin{array}{l}\text { Date of } \\
\text { Measurements }\end{array}$ & $\begin{array}{c}\text { Sites } \\
\text { Included }\end{array}$ & $\begin{array}{c}\text { Data rate } \\
\text { (sec) }\end{array}$ & $\begin{array}{c}\text { Cut-off } \\
\text { (degree) }\end{array}$ & $\begin{array}{c}\text { Session } \\
\text { length (hours) }\end{array}$ \\
\hline HGRN91 & 5-9 Nov 1991 & 24 & 15 & 15 & $4 \times 6$ \\
\hline HGRN93 & 4-6 May 1993 & 16 & 15 & 15 & $3 \times 12$ \\
\hline HGRN95 & 8-11 Aug 1995 & 13 & 15 & 15 & $3 \times 24$ \\
\hline HGRN97 & 18-21 Jun 1997 & 13 & 30 & 15 & $3 \times 24$ \\
\hline HGRN99 & 16-19 Jun 1999 & 15 & 30 & 15 & $3 \times 24$ \\
\hline
\end{tabular}

Table 3. The CEGRN epoch campaigns

\begin{tabular}{llcccc}
\hline $\begin{array}{l}\text { Campaign } \\
\text { name }\end{array}$ & $\begin{array}{l}\text { Date of } \\
\text { Measurements }\end{array}$ & $\begin{array}{c}\text { Sites } \\
\text { Included }\end{array}$ & $\begin{array}{c}\text { Data rate } \\
(\mathrm{sec})\end{array}$ & $\begin{array}{c}\text { Cut-off } \\
(\text { degree })\end{array}$ & $\begin{array}{c}\text { Session } \\
\text { length (hours) }\end{array}$ \\
\hline CEGRN94 & 2-6 May 1994 & 23 & 15 & 15 & $5 \times 24$ \\
CEGRN95 & 29 May-2 Jun 1995 & 31 & 30 & 15 & $5 \times 24$ \\
CEGRN96 & 10-15 Jun 1996 & $31+10$ & 30 & 15 & $5 \times 24$ \\
CEGRN97 & 4-10 Jun 1997 & $31+10$ & 30 & 15 & $5 \times 24$ \\
CEGRN99 & 14-19 Jun 1999 & 57 & 30 & 15 & $5 \times 24$ \\
\hline
\end{tabular}

The situation within the CEGRN network is more complex. As it is a multi-national network, still several more or less rigorous monumentation solutions exist. Over the tectonic significance the basic selection principle was that only forced-centred monumentation was accepted. Most of the sites were put into bedrock, but especially in the case of permanent stations compromises had to be made. The inclusion of the permanent stations is important because they have long-term continuous coordinate time series and they provide the connection to ITRF, the global reference frame. These stations are co-located with observatories and mainly they were put onto buildings. These cases the site stability monitoring was prescribed using local geodetic network and footprints located in the $10-50 \mathrm{~km}$ vicinity of the permanent station. PENC provides an excellent example for this kind of permanent station monitoring.

Beyond the well-defined multi-level (global-regionallocal) hierarchy of the GPS geodynamic networks the individual sites should also be connected to traditional geodetic networks. Most of the HGRN markers are levelled and gravimetric measurements had been also performed. The periodic re-occupation of the points with different techniques supports the tectonic interpretation.

\subsection{GPS Campaigns in the HGRN and CEGRN networks}

Carefully designed GPS campaigns have basic importance in GPS geodynamics. Selection of appropriate session length and repetition, receiver and antenna distribution, measurements in the same period of year are necessary in order to suppress systematic biases (daily and seasonal variations, antenna specific effects) in the results. These criteria are highly taken into account in the HGRN campaigns. We are observing three times 24 hours in the summer season in every second year. The first measurement campaign was performed in 5-9 November 1991, just following the EUREF CS/H91 campaign. The details of the five epoch campaigns may be found in Table 2. The organisation of the HGRN91 and HGRN93 was different from the subsequent campaigns. That time we had no adequate knowledge on the importance of full-day measurement cycles. Follow on studies revealed that the processing of sessions shorter than 24 hours may lead to biased results because of the daily periodic change of the atmospheric status. The sites in each campaign were occupied with different type of TRIMBLE receivers. In order to avoid antenna-specific systematic effects we tried to occupy the sites with the same antenna in the consecutive campaigns. The campaigns were organised yearly in about the same time of the year. This avoided seasonal effects. Each measurment lasted for five days continuously. Up to now five epoch campaigns have been performed, they are summarised in Table 3.

\subsection{GPS data processing}

The processing and evaluation of the HGRN and CEGRN campaigns was performed with the BERNESE V4.0 software package (Rothacher, M. et al., 1996). Both networks was treated as free network, which means that only one station was heavily constrained. The coordinate constraint was $0.1 \mathrm{~mm}$, which is practically equal to fixing the selected site. 
Accuracy of the final solutions of HGRN GPS campaigns

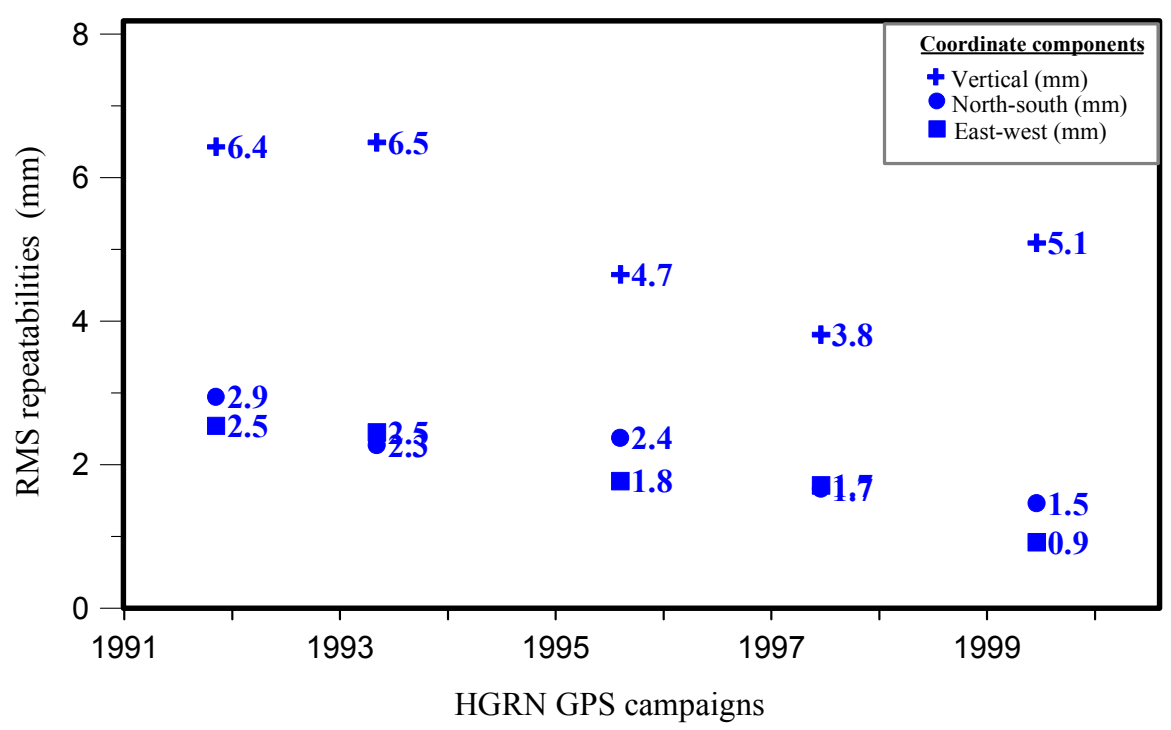

Fig. 5. Accuracy estimate for the campaign solutions of the HGRN in the three coordinate components based on daily repeatabilities.

Constraining versus direct fixing is advantageous when the consecutive campaigns are analysed in one procedure, where the constraint may need to be removed. Each campaign had been processed using the International Terrestrial Reference Frame; the ITRF96 where the ITRF96 coordinates of PENC (HGRN) and GRAZ (CEGRN) referring to the actual epoch of measurements was used.

The present version of the Bernese software uses doubledifferenced phase observables (the data of satellite and station pairs are differenced). This technique eliminates most of the systematic biases (SA, satellite and receiver clock errors) may be present in the data. The processing of each campaign was performed using precise GPS satellite orbits, provided by the CODE IGS Processing Centre (International GPS Service - Centre for Orbit Determination in Europe). The nominal accuracy of the precise ephemeris was $0.1 \mathrm{~m}$. Before the IGS started its service in 1993 the HGRN91 campaign had been processed using CIGNET (Co-operative International GPS Network) precise orbit, which had only about $0.5 \mathrm{~m}$ accuracy. The Bernese program estimates station coordinates using the L3 linear combination of the L1 and L2 observations. This kind of combination eliminates the ionospheric effect from the GPS data. The tropospheric effect had been modelled with the Saastamoinen model. In addition one tropospheric delay parameter for each two hours was estimated in order to handle better the temporal variation of the troposphere. The phase observation ambiguities were resolved using the so-called QIF (Quasi Iono Free) resolution strategy (see Rothacher et al., 1996).

The overall accuracy of each campaign was estimated from daily repeatabilities instead of using the internal accuracy estimation of the Bernese program. The formal or internal accuracy estimates are too optimistic because of the oversampling of phase data. The daily repeatabilities (the RMS scatter of the individual site coordinates computed from the session solutions) are kept much more realistic accuracy estimates. The accuracy parameters were derived in two steps. First the daily repeatabilities were computed for each site, which were then averaged. An example is shown in Fig. 5 about the accuracy estimates of the HGRN campaigns. The consecutive campaigns are characterised with $2 \mathrm{~mm}$ horizontal and 4-6 mm vertical accuracy with an improving trend in time. The CEGRN data analysis provided the same numbers, the RMS repeatabilities were around $1-3 \mathrm{~mm}$ in the horizontal components and 5-7 $\mathrm{mm}$ in the vertical. The increasing accuracy reflects the improvements in the GPS satellite constellation, precise orbit quality and the better campaign design. Taking the accuracy and the time span of both campaigns into account now we are able to detect horizontal tectonic displacement in the magnitude of $1 \mathrm{~mm} /$ year.

\section{Present crustal deformation, constraints from space geodesy}

The basic data of our interpretation are the daily coordinate and covariance files derived from the processing of each campaign. Computation of site velocities and strain rates was performed using the ADJCOORD 5.12UX and DISP 5.01UX software (Crook, 1992) and it was based on all four CEGRN observational campaigns from 1994 to 1997 and all HGRN campaigns from 1991 to 1999. Detailed analysis of the CEGRN results were previously published in Grenerczy et al. (1999). The simultaneous reduction method described by Bibby (1982) was used for the strain determination. The error values are given as $95 \%$ confidence estimates throughout the paper. 


\subsection{Site quality}

It is essential to check the site quality before the evaluation of the results. Despite these networks were built for measuring crustal deformation each site should be checked whether its data really reflects the tectonic movement. Therefore a site quality-monitoring program was also undertaken that checked the local geology, monumentation, antenna mounting, environment, multipath, interference, and the sky visibility obstruction above $15^{\circ}$. These inspections yielded important constraints concerning the reliability of the results at each site. A catalogue was created that contains the classification of the CEGRN sites based on the inspected factors above (Lévai et al., 1998).

Concerning the CEGRN network Lévai et al., (1998) showed that POLO and SKPL sites had the highest multipath effect in the network and SKPL had extremely big obstruction above $15^{\circ}$ because of the nearby mountain peaks. Hefty, (1999) has reported that the Slovakian sites MOPI and SKPL had phase centre excentricity problem, the actual antenna model differs from the IGS model. The phase centre corrections could not be determined for each campaign. The Romanian sites were not measured in 1994, the markers observed in 1995 were damaged at GILA, IASI and TISM (Becker et al., 1998). New sites were monumented in 1996 but the eccentricities could not be well determined. Therefore the apparent displacements between consecutive years show 10$20 \mathrm{~mm}$ variations. The fourth Romanian site, MACI had also two excentricity changes. We have omitted the data of every problematic site because of the highest accuracy and reliability requirements. Consequently the above seven sites are not included in the interpretation therefore the Apuseni Mountains and Southern Carpathians are not represented in the further calculations. The other sites of the CEGRN meet the requirements of the highest precision GPS measurements concerning its monumentation, antenna mounting, environment, multipath, interference and the sky visibility obstruction above $15^{\circ}$ (Lévai et al., 1998).

The site quality factors like the monumentation, antenna mounting, environment; multipath, interference and the sky visibility obstruction are undoubtedly satisfied at the HGRN sites. However in 1997 newly used TR L1/L2 GP antennas at HOLL and BUDA behaved differently from the IGS antenna phase centre model, therefore these sites were remeasured with 4000ST L1/L2 GEOD antennas in the same year. However, these two antennas were used at the same two sites during the HGRN99 as well and they have not been remeasured yet. Thus the remeasured ' 97 data are used and ' 99 data of BUDA and HOLL were rejected. In 1999 at CSER site we used at the first time T4700 antennas without testing it and we relied on the IGS phase centre model. There is a great and continuously increasing need of GPS antenna calibration, therefore we have established a GPS calibration network and worked out the calibration procedures. These antennas are going to be tested in the near future but till that time we should reject or be careful with these antennas. Nonetheless, the 4000ST L1/L2 GEOD antennas, the major- ity of our equipment, have been thoroughly tested and all of them behave according to the IGS model and their phase centres are identical.

\subsection{Reference frame}

In order to establish a common reference frame for the CEGRN observational campaigns seven IGS stations were selected from the CEGRN sites (BOR1, GOPE, GRAZ, JOZE, LAMA, PENC, and WTZR). These stations have rms in each velocity component smaller than $1 \mathrm{~mm} / \mathrm{yr}$ in the ITRF96 reference frame. Using their ITRF96 coordinates and velocities we computed their coordinates in the actual epoch of the CEGRN observational campaigns. Between these reference coordinate sets and the processed CEGRN daily coordinate sets 6 parameter Helmert transformation was performed. To obtain the intraplate velocities the common motion of the GPS sites due to the Eurasia plate motion is removed using the NNR-NUVEL1A (DeMets et al., 1990, 1994) rigid plate model velocity for Eurasia (McCarthy, 1996). However, we investigated and found that constraining only one station, GRAZ, to the ITRF96 instead of seven IGS sites had no significant effect on the estimated coordinates. Furthermore, removing the common plate motion of Eurasia by Helmert transformation between the epochs resulted the same intraplate velocities to better than $0.5 \mathrm{~mm} / \mathrm{yr}$ at each site in both directions. There was no detectable remaining rotation or shift between the two solutions. Concerning the Hungarian network its small extent explains why we chose the latter approach and tying the HGRN campaigns to the ITRF96 with the use of the ITRF96 coordinates and velocities of PENC station.

\subsection{Rigidity of plate interior}

We now investigate how consistent our result is with the average rates over the last few million years derived from geological records and other geophysical data. Thus we compared the velocities we observed using GPS in the ITRF96 with those of the NNR-NUVEL1A model (Fig. 6). The NNR-NUVEL1A is a rigid plate model whereas the GPS derived velocities contain intraplate movements as well. Therefore their comparison shows not only the consistency between space geodetic data and geological and geophysical observations but indicates where and how rigid the plate is, and where the considerable internal deformations are. In the region of the CEGRN, the NNR-NUVEL1A velocity of the Eurasian plate is $24 \mathrm{~mm} / \mathrm{yr}$ oriented at $57^{\circ}$. Within the network the largest difference between the NNRNUVEL1A model velocities at the CEGRN sites does not exceed $1 \mathrm{~mm} / \mathrm{yr}$ and $7^{\circ}$ in the orientation. The ITRF velocities derived from the GPS campaigns seem to be similar and show plate rigidity at $1-2 \mathrm{~mm} / \mathrm{yr}$ level in the greater part of Central Europe. These values are similar to those for Eastern North America (Dixon et al., 1996). The largest differences between the NNR-NUVEL1A model and the ITRF velocities, indicating intraplate deformation, come from the 


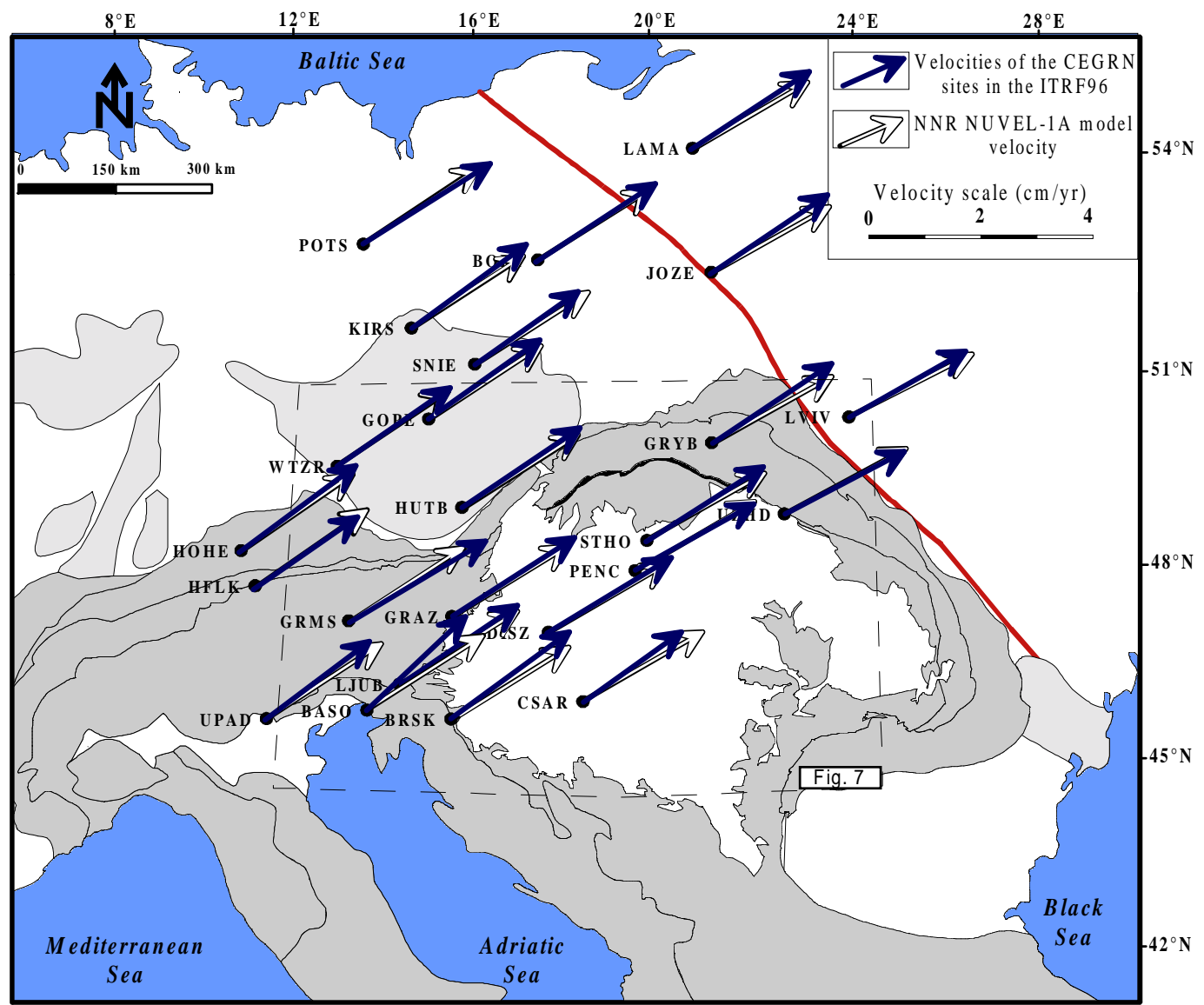

Fig. 6. Comparison of GPS derived velocities in the ITRF96 reference frame with the NNR-NUVEL1A model velocities at the CEGRN sites.

Alpine-Pannonian-Dinaric region and exceed $4 \mathrm{~mm} / \mathrm{yr}$ and $10^{\circ}$ at BASO site near the boundary of the Adriatic microplate. Smaller inconsistencies, not exceeding the $2 \mathrm{~mm} / \mathrm{yr}$ level, also were found at the northern sites in the German Polish Depression and the Precambrian Platform.

\subsection{Intraplate crustal movements in and around the Pan-} nonian basin

We have compiled an intraplate velocity map for the PANCARDI region based on three different sources (Fig. 7). There are six continuously observing GPS permanent stations in the study area that are part of the global IGS network and represented in the ITRF96 solution. There is a regional geodynamic GPS network, the CEGRN with fifteen sites in the region and finally the Hungarian national network, the HGRN, has thirteen GPS sites mainly in the inner part of the Pannonian basin. The given error estimates (sigma) for the ITRF velocities are $0-0.2 \mathrm{~mm} / \mathrm{yr}$ in the horizontal component that is very optimistic and obviously represents only the formal errors. Therefore the ITRF97 velocities beside the ITRF96 are also shown for the same IGS sites of the region in order to better estimate the errors of the ITRF solutions.

The inner coordinate solution was used for the CEGRN and HGRN intraplate velocity fields on Fig. 7. It is only weakly dependent on any particular station and provides the best choice for a large and complex area without apriori knowledge of the ongoing deformations. The inner coordinate solution minimises the sum of squares of the velocity components and requires that the centre of mass of the network remains stationary (Prescott, 1981). In case of interplate areas or along known strike slip faults other solutions may be preferred but inside the Eurasian plate in a relatively large area with presumably complex velocity field we chose this solution for the interpretation. In order to make the ITRF solution comparable, WTZR was constrained to move with the velocity of the CEGRN solution and the ITRF velocities are given relative to WTZR. The reasons for choosing WTZR are the followings: It represents the most precise velocities in the ITRF solutions. It has collocated VLBI and SLR instruments and one of the longest continuous observations and situated in a tectonically calm area.

PENC station is part of each network mentioned and since GRAZ was included in the HGRN processings these two sites have velocities from three different networks, measurements and processings. There are two sites WTZR and GOPE that are part of both the CEGRN and IGS networks and two sites, DISZ and CSAR, which are part of the HGRN 


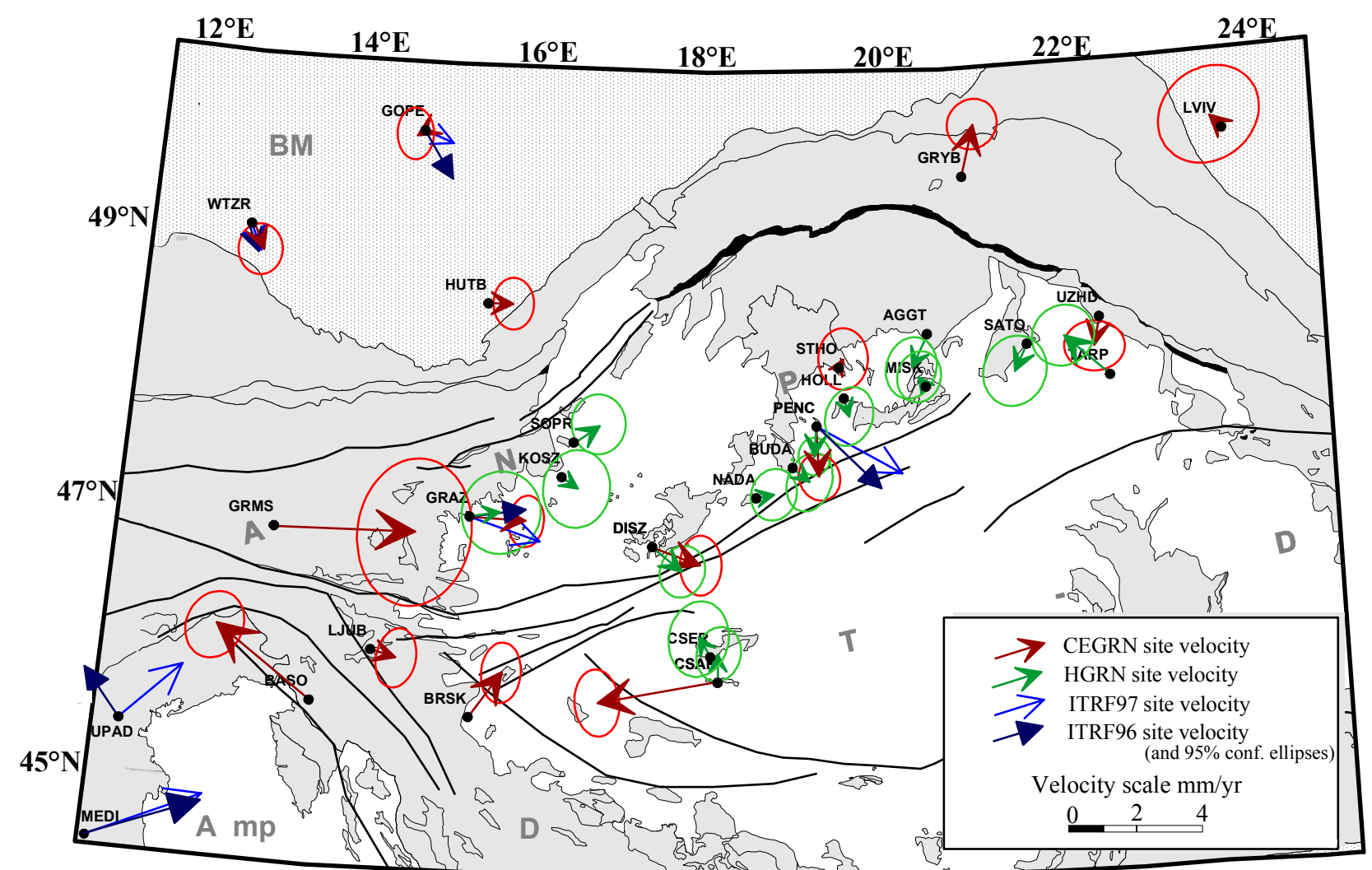

Fig. 7. Intraplate crustal velocities in the PANCARDI region. The velocities are from the ITRF96 and ITRF97 solutions of IGS sites (dark and light blue arrows resp.), 4 GPS campaigns of CERGOP sites (red arrows), and 5 GPS campaigns of the HGRN sites (green arrows). The error limits are $95 \%$ confidence estimates. The solid black lines are indicating the major seismoactive faults separating crustal blocks after Gerner et al. (1999). ANP: Alpine-North Pannonian unit; BM: Bohemian Massif; A mp: Adriatic microplate; T-D: Tisza-Dacides unit; D: Dinaric block.

and the CEGRN networks. For these four sites two different velocities can be found on Fig. 7. The HGRN and the CEGRN solutions generally very well agree at all common sites (DISZ, GRAZ and PENC) except for CSAR. Here the dissimilarity is obvious and most probably resulted by the last two HGRN campaigns since the CEGRN velocity is very similar to that derived from the HGRN campaigns from 1991 to 1995 (Grenerczy, 1998). The ITRF96 and ITRF97 velocities of GOPE and UPAD show considerable difference whereas those of other IGS sites of the region are very similar. Small but significant differences may be observed between the CEGRN and the ITRF solutions as well at GOPE and PENC whereas at WTZR and GRAZ the velocities are almost identical.

As expected the largest velocities can be found in the southwest at the Alpine-Adriatic collision zone. UPAD and MEDI sites probably represent the movement of the Adriatic microplate whereas BRSK, LJUB and BASO are situated in the Adriatic-Alpine-Dinaric triple junction. For clarity major seismoactive faults, separating the crustal blocks are also indicated on Fig. 7 after Gerner et al. (1999). All the above sites show northward crustal movement in the range of 1.5$2 \mathrm{~mm} / \mathrm{yr}$. As a complementation of the south-western region the results of the CRODYN (the Croatian GPS geodynamic network) - according to Altiner et al. (1999) - show generally northward oriented velocities along the Croatian coastline from Dubrovnik through Zadar to BASO site with reference to GRAZ. The direction of these velocities turns to north-west towards the northern parts (see Fig. 2 of Altiner et al. (1999)) and at BASO site their velocity orientation is similar to that derived from the CEGRN. However, the magnitudes of the CRODYN velocities are three times higher (about $1 \mathrm{~cm} / \mathrm{yr}$ ) than that of the CEGRN. The results of the CEGRN presented on Fig. 7 are undoubtedly more reliable and probably represent the actual value. These results are based on four 5-day campaigns and their magnitudes agree with the permanent observations represented by the ITRF solutions whereas the CRODYN results are based on only two 3-day measurements having much larger errors. Nevertheless the preliminary CRODYN results represent a very important region and great value from the point of view of the geodynamics of the PANCARDI region because it also proves the northward movement of the Adriatic region and also supports the presence of the north-south compression. Five sites representing the western part of the Alpine-North Pannonian unit all show eastward crustal velocities that in- 


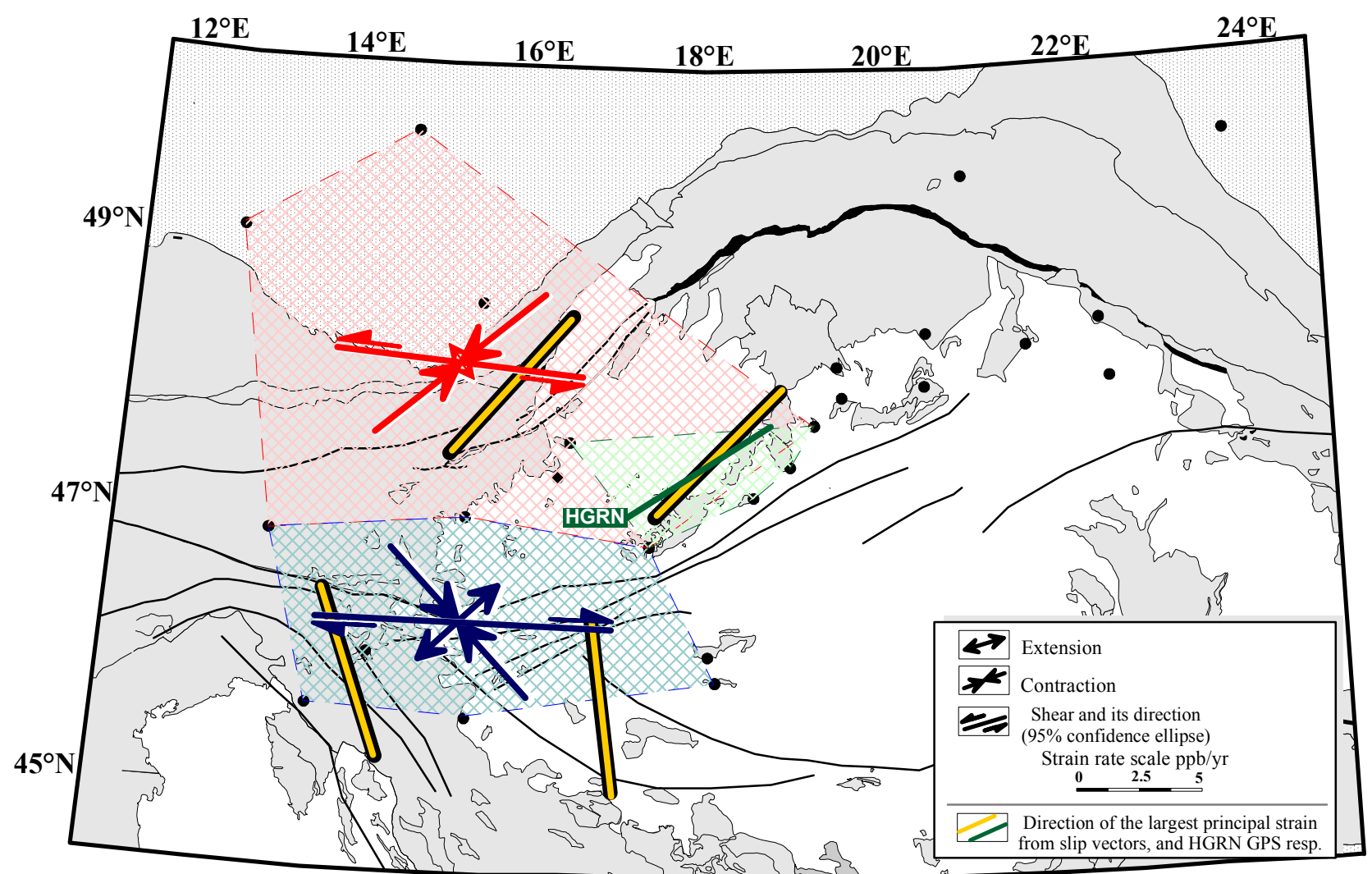

Fig. 8. Principal strain rates and their direction for two subnetworks crossing the northern and southern boundary of the Alpine-North Pannonian unit (Red and Blue). Yellow lines show the dominating trends of strain direction from extrapolation and interpolation of horizontal component of slip vectors obtained from earthquake focal mechanism solution (Bada et al., 1999). Green line shows the direction of contraction for the western part of the HGRN network derived from GPS measurements (Grenerczy, 1998).

side the Pannonian basin seem to become divergent. The magnitude of the eastward movement of the unit is in the range of $4 \pm 2 \mathrm{~mm} / \mathrm{yr}$ at the westernmost site in the Eastern Alps and $1-1.5 \pm 0.7 \mathrm{~mm} / \mathrm{yr}$ inside the Pannonian basin. In the eastern sections there are many sites with hardly or not significant velocities. However, the three south-western velocities are remarkable in the north-east because both $\mathrm{CE}$ GRN and HGRN sites behave similarly. Although the northward movement of GRYB in the Western Carpathians is significant, one site from a region is not enough for certain conclusions. In the north the Bohemian Massif looks fairly stable. There is no crustal movement above $1 \mathrm{~mm} / \mathrm{yr}$ except for the ITRF96 solution of GOPE. This is two times smaller in the later solution, ITRF97. The results of the Czech GEODYN project also prove the rigidity of the Bohemian Massif under $1 \mathrm{~mm} / \mathrm{yr}$ level (Simek, 1999). LVIV is the only site in the Eastern European Precambrian Platform. Here we did not observed significant crustal movement.

The whole picture of crustal velocities on Fig. 7 suggests that the northward moving Adriatic region presently squeezes out the western part of the Alpine-North Pannonian unit to the east towards the Pannonian basin from between the stable, hardly deforming Bohemian Massif and the Adri- atic microplate. It seems likely that the eastward escape is absorbed in the central section of the Alpine-North Pannonian unit in the Pannonian basin since no detectable eastward component found for the site velocities in the eastern, northeastern part of the unit.

\section{Strain pattern in the PANCARDI region}

To get insight into the horizontal deformation pattern of the study area we have calculated the principal strain rates for two subnetworks of the CEGRN (Fig. 8). They were chosen to represent enough sites for accuracy and to have good geometry for better resolution of strain in all directions. The common sites of these subnetworks are all situated on the Alpine-North Pannonian unit thus the fault zones at its borders are spanned by the subnetworks. The largest principal strain rate is a contraction in both regions indicating the ongoing Alpine collision that is detectable at least to the Bohemian Massif. The azimuth of principal contraction at the northern part of the Alpine zone is NE-SW $\left(52^{\circ} \pm 7^{\circ}\right)$ with rate of $-8.6 \pm 2.5 \mathrm{ppb} / \mathrm{yr}$, over $300 \mathrm{~km} \times 300 \mathrm{~km}$ area. The orientation of contraction changes to NW-SE $\left(138^{\circ} \pm 13^{\circ}\right)$ perpendicular to the previous in the south with a similar rate of 
$-8.0 \pm 5.3 \mathrm{ppb} / \mathrm{yr}$ over the $300 \mathrm{~km} \times 120 \mathrm{~km}$ southern subnetwork. Concerning the shear strains we found that the orientation of the maximum shear rate is very similar in both the southern and northern regions, $93^{\circ} \pm 13^{\circ}, 97^{\circ} \pm 7^{\circ}$ at rates of $12 \pm 5 \mathrm{ppb} / \mathrm{yr}, 10 \pm 2 \mathrm{ppb} / \mathrm{yr}$ respectively. Whereas at the southern border of the Alpine-North Pannonian unit dextral shear was observed, at the northern boundary sinistral shear was detected. The two parallel east-west oriented shear direction coincides with the primary fault systems of the region (Fig. 8) indicating that these fault zones should have present activity, mainly of strike slip character. The observed contraction implies thrust faulting should also be present. Earthquake focal mechanism solutions support these types of fault kinematics (Gerner et al., 1999). On Fig. 8 the smoothed directions of horizontal component of slip vectors from earthquake focal mechanism solutions are also indicated after Bada et al. (1999) along with the largest principal strain direction of the western section of the HGRN (Grenerczy, 1998). These strain rates first time directly measured by space geodesy validate and quantify the similar strain pattern derived from seismic data. Strain calculations also support that the movement of the Adriatic microplate has a compressional effect in the Alpine zone that causes the observed roughly north-south contraction that changes from NW-SE to NE-SW from south to north. It squeezes out the AlpineNorth Pannonian unit from between the Adriatic microplate and the rigid Bohemian Massif along a roughly east-west sinistral shear zone in the north and dextral shear zone in the south. This eastward escape and its magnitudes can be seen in the calculated intraplate crustal velocity field (Fig. 7).

\section{Summary}

Space geodesy has brought the era when we are able to directly measure the present crustal deformations. Several space geodetic projects have been commenced in the PANCARDI region during the nineties. As the time base increases these results become more and more accurate and reliable. To date there is only one regional GPS network that covers the whole region of the Pannonian basin system. The CEGRN has already provided valuable results that will probably be strengthened by the data from the second phase of the project. The network being a regional reference network, its spatial resolution is inadequate to constrain the crustal deformation pattern in fine detail. Densification by national and local investigations should complement the large-scale picture. The unification of smaller scale e.g. national networks could provide the best spatial resolution, however the data quality would be inhomogeneous.

\section{References}

Altiner, Y., Colic, K., Marjanovic, M., Medic, Z., Medved, M., Miskovic, D., Rasic, L., Pribicevic, B., Seeger, H., and Szabó, M.: Is the Adriatic Sea a Promontory or Exists as an Independent Microplate? Reports on Geodesy No. 5(46), 149-157, 1999.
Bada, G., Cloetingh, S. A. P. L., Gerner, P., and Horváth, F.: Sources of recent tectonic stress in the Pannonian region inferences from finite element modelling, Geophysical Journal International, 134, 87-102, 1998.

Baran, L. W., Busics, I., Cacon, S., Dobrzycka, M., and Zablotsky, F.: Status of subregional GPS geodynamics project GEODUC, Proceedings of the 1st Turkish International Symp. on Deformations, Istambul, 1994.

Becker, M., Ghitau, D., Marcu, C., Radulescu, F., Reinhart, E., Rosca, V., Rus, T., and Seeger, H.: Plate kinematics studies in Romania using GPS, Reports on Geodesy, 9 (39), 89-103, 1998.

Bibby, H. M.: Unbiased estimate of strain from triangulation data using the method of simultaneous reduction, Tectonophysics, 82 , 161-174, 1982.

Crook, C. N.: ADJCOORD: A FORTRAN program for survey adjustment and deformation modelling. NZGS EDS Rep. Geol. and Geophys., Dept. of Sci. and Ind. Res., Lower Hutt, New Zealand, 138, 22 pp., 1992.

DeMets, C., Gordon, R. G., Argus, D. F., and Stein, S.: Current plate motions, Geophys. J. Int., 101, 425-478., 1990.

DeMets, C., Gordon, R. G., Argus, D. F., and Stein, S.: Effect of recent revisions to the geomagnetic reversal time scale on estimates of current plate motion, Geophys. Res. Lett., 21, 21912194, 1994.

Dixon, T. H., Mao, A., and Stein, S.: How rigid is the stable interior of the North American plate?, Geophys. Res. Lett., 23, 30353038, 1996.

Erker, E., Imrek, E., Pesec, P., Stangl, G., and Sünkel, H.: Das Österreichische Geodynamische Bezugssystem AGREF, Realisierung und Ergebnisse. Sonderausgabe des Institutes für Weltraumforschung der Österreichischen Akademie der Wissenschaften, Abteilung Satellitengeodaesie, 1997.

Fejes, I.: Proposed Two-step Observing Monument Applicable to High Precision Surveying by GPS, SGMS Newsletter, 2, 2, 1991.

Fejes, I., Borza, T., Busics, I., and Kenyeres, A.: Realization of the Hungarian Geodynamic GPS Reference Network. J. Geodynamics, 18, 145-152, 1993.

Fejes, I., Ghitau, D., Marchesini, C., Mojzes, M., Pesec, P. Reinhart, E., Simek, J., Sledzinski, J., Solaric, M., Vodopivec, F., and Zablotskij, F.: The Central Europe Regional Geodynamics Project (CERGOP): Main achievements. Proc. 23th General Assembly of the European Geophysical Society, Symp. G16, Nice, France, 20-24 April 1998. Reports on Geodesy, 9(39), 21-39, 1998.

Fejes, I.: New Developments in the CERGOP Concept. Invited presentation at the International Seminar on GPS in Central Europe, 5-7 May 1999, Penc, Hungary. Reports on Geodesy, 5(46), 133$142,1999$.

Gerner, P., Bada, G., Dövényi, P., Müller, B., Onescu, M. C., Cloetingh, S. A. P.L., and Horváth, F.: Recent tectonic stress and crustal deformation in and around the Pannonian basin: Data and models, in: Durand, B., Jolivet, L., Horváth, F., and Séranne, M.: The Mediterranean Basins: Tertiary Extension Within the Alpine Orogen, edited by Geol. Soc. London Spec. Publ., 156, 269-294, 1999.

Ghitau, D.: Report of the CERGOP Study Group 11: Three dimensional plate kinematics in Romania, Reports on Geodesy, Warsaw University of Technology, 10(40), p.249, 1998.

Grenerczy, Gy.: Crustal deformations in the Pannonian basin inferred from GPS measurements, Reports on Geodesy, 9(39), 377-384, 1998. 
Grenerczy, G., Kenyeres, A., and Fejes, I.: Present crustal movement and strain distribution in Central Europe inferred from GPS measurements, Journal of Geophys. Res., 105, B9, 21 835$21846,2000$.

Hefty, J.: Problems of Antenna Phase Center Correction in Epoch and Permanent Geodynamic GPS Observations, Reports on Geodesy, 5(46), 205-213, 1999.

Joó, I., Czobor, Á., Gazsó, M., and Németh, Zs.: On the recent crustal movement in the Pannonian basin, Acta Geod.Geoph. Mont. Hung., 25, 1990.

Lévai, P., Borza, T., Fejes, I., Kujawa, L., and Mojzes, M.: Final report of CERGOP Study Group No.2: Site Quality Monitoring, Reports on Geodesy, 10(40), 115-168, 1998.

Marchesini, C.: Final report of the CERGOP Study Group 10 Monitoring of Recent crustal movements in the Eastern Alps with GPS. Reports on Geodesy, Warsaw University of Technology, 10(40), p 245, 1998.
McCarthy, D. D. (Ed.): IERS Conventions, IERS Technical Note 21, Observatoire de Paris, 1996.

Prescott, W. H.: The determination of displacement fields from geodetic data along a strike-slip fault, Journal of Geophys. Res., 86, 6073-6090, 1981.

Priam, S.: National Report of Slovakia. Report on Geodesy, Warsaw University of Technology, 1(14), 1995.

Rothacher, M., Beutler, G., Gurtner, W., Brockman, E., and Mervart, L.: Bernese GPS software version 4.0 documentation 1996, Astron. Inst., Univ. of Bern, Bern, Switzerland, 1996.

Simek, J.: Geodynamical Network of the Czech Republic and National Densification of EUVN paper presented at the 5th International Seminar on GPS in Central Europe, 5-7 May 1999, Penc, Hungary, 1999.

Sledzinski, J.: Satellite Geodetic Traverses (SAGET) in Central and Southern Poland, Reports on Geodesy, 1(3), p. 7, 1991.

Solaric, M.: Personal communication, 1999. 